\title{
Pengembangan Media Pembelajaran Game Education pada Mata Pelajaran Bahasa Inggris Materi My Body Rosidiana Ma'rufah ${ }^{1, a}$, *Abdul Ghoni ${ }^{2, b}$ \\ ${ }^{1,2}$ Institut Agama Islam Negeri, Salatiga, Jawa Tengah, Indonesia

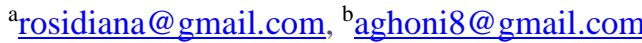

\begin{abstract}
:
The media game of education in this study referred to the overview of the basic body along with pictures to attract students' attention. The type of research used in this study was Research and Development $(R \& D) . R \& D$ is a research strategy or method that is powerful enough to improve practice. The data were collected through questionnaires, interviews, and documentation. The object was to measure the success of the learning process as evidenced by the student's scores. The variable used as a measurement was the feasibility of the product. The results showed that the need for game education in learning was an important medium to make the teachers easier delivering the learning material, attracting students, especially for grade 1 students at Madrasah Ibtidaiyah, students were also easier to master the topic about my body. The development of learning media for game education can be used by students not only when learning at school. The effectiveness test using the SPSS program also showed the value of Sig. (2-tiled) $\mathrm{p}=0.000<0.05$, which means that game media education was effective to improve English learning outcomes about my body.
\end{abstract}

Keywords: Learning Media, Game Education

\section{Abstrak:}

Media game education pada penelitian ini berisi tentang materi pengenalan anggota tubuh dasar disertai dengan gambarnya sehingga lebih menarik minat siswa. Jenis penelitian yang digunakan dalam penelitian ini adalah Research and Development (R\&D). R\&D merupakan sebuah strategi atau metode penelitian yang cukup ampuh memperbaiki praktik. Data dikumpulkan melalui angket, wawancara serta dokumentasi. Objek penelitian adalah untuk mengukur kesuksesan proses pembelajaran yang dibuktikan dengan hasil nilai siswa. Variabel yang digunakan sebagai tolak ukur yakni kelayakan dari produk. Hasil dari penelitian ini menunjukkan bahwasanya kebutuhan media pembelajaran game education merupakan media yang penting digunakan untuk mempermudah guru dalam menyampaikan materi pembelajaran, menarik minat siswa khususnya siswa kelas 1 Madrasah Ibtidaiyah serta mempermudah siswa dalam menguasai materi tentang my body, pengembangan media pembelajaran game education mampu dioperasikan sendiri oleh siswa tidak hanya saat pembelajaran di sekolah, uji efektivitas menggunakan program SPSS menunjukkan nilai Sig. (2-tiled) $p=0,000<0,05$, yang berarti media game education efektif dalam meningkatkan hasil pembelajaran Bahasa Inggris materi my body.

Kata Kunci: Media Pembelajaran, Game Edukasi

Cara mensitasi artikel ini:

Ma'rufah, R., \& Ghoni, A. (2021). Pengembangan Media Pembelajaran Game Education pada Mata Pelajaran Bahasa Inggris Materi My Body. Mitra PGMI: Jurnal Kependidikan MI, 7(1), 40-48. https://doi.org/10.46963/mpgmi.v7i1.221

\section{INFORMASI ARTIKEL}

*Corresponding author: aghoni8@gmail.com

DOI: https://doi.org/10.46963/mpgmi.v7i1.221

\section{Histori Artikel:}

$\begin{array}{ll}\text { Diterima } & : 17 / 11 / 2020 \\ \text { Direvisi } & : 11 / 01 / 2021 \\ \text { Diterbitkan } & : 25 / 01 / 2021\end{array}$

\section{PENDAHULUAN}

Proses pembelajaran merupakan sistem yang terdiri dari komponen-komponen guru, siswa, tujuan, bahan materi, fasilitas, strategi dan penilaian. Seluruh komponen 
tersebut tidak mampu berdiri sendiri, karena seluruh komponen tersebut saling berhubungan. Dalam proses pembelajaran seorang guru harus menggunakan berbagai cara sebagai strategi dalam menyajikan materi kepada siswa (Junaedi Nugraha, 2020). Pada proses belajar mengajar ada dua unsur yang sangat penting, yakni metode pengajaran serta media pengajaran. Media pelajaran menunjukkan keunggulannya dalam membantu para pendidik atau pengajar dalam proses menyampaikan pesan pembelajaran serta lebih cepat dan mudah ditangkap oleh anak-anak didik (Aminudin, 2014).

Media atau medium (bahasa latin) sendiri memiliki arti perantara. Assosiation for education and communication technology (AECT) mendefinisikan media merupakan segala bentuk yang dipergunakan untuk suatu proses penyaluran informasi (Farouq, 2015). Penggunaan media dalam pembelajaran dapat meningkatkan kualitas pembelajaran. Selain itu mempermudah siswa di dalam memahami materi yang dipelajari (Lestari, Hadi, \& Mushafanah, 2019). Media ajar merupakan salah satu jenis media pendidikan. Media ajar adalah media yang berisi uraian bahan tentang mata pelajaran atau bidang studi tertentu, yang disusun secara sistematis dan telah diseleksi berdasarkan tujuan tertentu, orientasi pembelajaran, dan perkembangan siswa, untuk diasimilasikan. Kedudukan media yang merupakan alat bantu mengajar ada dalam komponen metodologi, sebagai salah satu lingkungan belajar yang diatur oleh guru untuk mempertinggi proses interaksi guru dan siswa dan interaksi siswa dengan lingkungan belajarnya (Isran Rasyid Karo-Karo S, 2018).

Game education merupakan salah satu media pembelajaran yang cukup menarik untuk dikembangkan. Game sering kali dituduh memberikan pengaruh negatif terhadap anak. Sebenarnya, game memiliki kegunaan dan dampak baik bagi anak, sehingga anak dapat mengenal teknologi, pembelajaran untuk mengikuti arahan dan aturan, melatih menyelesaikan masalah, melatih saraf motorik dan keterampilan spesial, menjalin komunikasi saat bermain serta memberikan hiburan bagi anak (Nozomi, 2018). Berdasarkan hasil penelitian yang telah dilakukan sebelumnya, terbukti bahwa game education mampu menunjang proses pendidikan. Keunggulan lainnya yakni adanya animasi yang dapat meningkatkan daya ingat siswa sehingga anak dapat menyimpan materi pelajaran dalam waktu yang lebih lama dibandingkan dengan metode pengajaran konvensional (Vitianingsih, 2016).

Pada siswa sekolah usia dasar, belajar bahasa Inggris merupakan suatu hal yang baru, karena di saat inilah mereka biasanya baru memulai mengenal beberapa kosakata dasar dalam Bahasa Inggris, dan di usia mereka tersebut, menerima hal baru merupakan suatu hal yang sangat menyenangkan. Pada tahap usia ini mereka akan lebih mudah menyerap hal dan ilmu baru. Oleh sebab itu, sebaiknya guru sebagai fasilitator serta pendamping belajar mampu mengoptimalkan penggunaan media pembelajaran yang sesuai dengan usia mereka agar hasil pembelajaran lebih maksimal.

Berdasarkan hasil observasi dan wawancara terhadap guru kelas I MI di Kota Salatiga , sarana dan prasarana yang menunjang pembelajaran Bahasa Inggris begitu 
minim terutama dalam materi My Body. Dari pihak sekolah juga mengakui bahwa sekolah hanya memiliki buku LKS yang isinya hanya materi di gunakan dalam pembelajaran. Sistem pembelajaran Bahasa Inggris yang ada biasanya hanya mendengarkan guru ceramah di depan kelas tanpa memanfaatkan media. Hal ini menyebabkan siswa kurang tertarik dengan materi yang disampaikan sehingga siswa kurang memahami materi yang di sampaikan. Hasil observasi yang dilakukan di kelas, terlihat siswa tidak memperhatikan pembelajaran dengan baik serta kemampuan memahami materi pelajaran masih cukup rendah.

Berdasarkan permasalahan tersebut, maka perlu diadakan penelitian mengenai pengembangan media pembelajaran game education untuk peserta didik SD/MI yang berisi materi My Body yang dapat digunakan sebagai sumber belajar yang mampu meningkatkan minat dan motivasi peserta didik.

\section{METODE}

\section{Metode Pengembangan}

Metode yang digunakan dalam penelitian ini adalah metode pengembangan atau Research and Development. Penelitian dan pengembangan atau Research and Development adalah metode penelitian yang digunakan untuk menghasilkan produk tertentu dan menguji keefektifan produk tersebut. Penelitian ini dilakukan pada siswa kelas I Madrasah Ibtidaiyah di Kota Salatiga (MI Ma'arif Mangunsari dan MI Tarbiyatul Islamiyah Noborejo) dengan jumlah 47 siswa.

\section{Model dan Prosedur Pengembangan}

Penelitian ini dirancang dengan menggunakan model pengembangan pembelajaran Walter Dick and Lou Carey. Adapun langkah-langkah tersebut antara lain adalah :

a. Identifying Instructional Goal (mengidentifikasi tujuan umum pembelajaran).

b. Conducting Instructional Analysis (melaksanakan analisis pembelajaran).

c. Identifying Entry Behaviors, Characteristics (mengenal tingkah laku masukan dan karakteristik siswa).

d. Writing Performance Objectives (merumuskan tujuan khusus pembelajaran).

e. Developing Criterion-Referenced Test (mengembangkan butir tes acuan patokan).

f. Developing Instructional Strategy (mengembangkan strategi pembelajaran).

g. Developing and selecting Instruction (menyeleksi dan mengembangkan bahan pembelajaran).

h. Designing and Conducting Formative Evaluation (merancang dan melaksanakan evaluasi formatif).

i. Revising Instruction (merevisi bahan pembelajaran).

j. Designing and Conducting Summative Evaluation atau merancang dan melaksanakan evaluasi sumatif (Rumainur, 2016). 
Rosidiana Ma'rufah, Abdul Ghoni

Pengembangan Media Pembelajaran Game Education pada Mata Pelajaran Bahasa Inggris..

\section{Uji Coba Produk}

\section{a. Desain Uji Coba}

Tahap penilaian yang dilaksanakan dalam pengembangan ini adalah tahap konsultasi, tahap validasi ahli, dan tahap uji coba lapangan berskala kelompok besar. Masing-masing tahap ini dapat dijelaskan sebagai berikut.

1) Tahap Validasi Ahli

Tahap validasi ahli terdiri dari beberapa kegiatan berikut.

a) Ahli materi, ahli desain pembelajaran, ahli bahasa, dan ahli pembelajaran memberikan penilaian dan masukan berupa kritik dan saran terhadap media ajar yang dihasilkan, yakni Bapak Teguh.

b) Pengembang melakukan analisis data penilaian dan masukan berupa kritik dan saran.

c) Pengembang melakukan perbaikan media ajar berdasarkan kritik dan saran.

Validasi ini disebut validasi isi (content) dan validasi desain media pembelajaran yang diperoleh melalui penilaian dan tanggapan dari para ahli dengan mengisi angket dan memberi masukan atau saran terhadap media ajar.

2) Tahap Uji Coba Lapangan

Uji coba lapangan terdiri dari beberapa kegiatan berikut.

a) Pengembangan mengamati siswa yang sedang belajar menggunakan media ajar hasil pengembangan.

b) Siswa memberikan penilaian terhadap media ajar hasil pengembangan.

c) Pengembang melakukan analisis data hasil penilaian.

d) Pengembang melakukan perbaikan media ajar berdasarkan hasil analisis penilaian.

\section{b. Subyek Uji Coba}

Subyek penilaian dalam pengembangan media ajar ini terdiri atas:

1) Ahli Materi

Bertindak sebagai ahli materi dalam pengembangan media ajar ini adalah seorang magister di bidang pendidikan.

2) Ahli Desain Pembelajaran

Bertindak sebagai ahli media dalam pengembangan media ajar ini adalah seorang yang ahli dalam bidang desain dan media pembelajaran.

3) Ahli Bahasa

Bertindak sebagai ahli bahasa dalam pengembangan media ajar ini adalah seorang dosen Bahasa Inggris.

4) Ahli Pembelajaran

Ahli pembelajaran yang memberikan tanggapan dan penilaian terhadap media ajar ini adalah guru kelas I yang sehari-hari mengajar di Madrasah Ibtidaiyah di Kota Salatiga. 
5) Siswa Madrasah Ibtidaiyah di Kota Salatiga

Uji coba lapangan dilakukan pada Semester gasal tahun ajaran 2018/2019. Subyek uji coba lapangan ini adalah siswa kelas I Madrasah Ibtidaiyah di Kota Salatiga.

\section{c. Jenis Data}

Data yang diungkapkan dalam tahap hasil uji coba ini adalah:

1) Ketepatan dan keefisienan atau validitas isi/materi media ajar diperoleh dari ahli materi.

2) Ketepatan dan kemenarikan desain media ajar diperoleh dari ahli desain pembelajaran.

3) Ketepatan dan keefisienan bahasa media ajar diperoleh dari ahli bahasa.

\section{d. Instrument Pengumpulan Data}

Instrumen yang digunakan dalam pengumpulan data pada pengembangan ini berupa angket. Angket ini ditujukan untuk subyek uji coba. Adapun angket yang dibutuhkan adalah: (a) angket penilaian ahli materi, (b) angket penilaian ahli desain pembelajaran, (c) angket penilaian ahli bahasa, (d) angket penilaian ahli pembelajaran, dan (e) angket penilaian siswa uji coba lapangan.

\section{e. Teknik Analisis Data}

Teknik analisis data dalam penelitian ini adalah mendeskripsikan semua pendapat, saran dan tanggapan validator yang didapat dari lembar kritik dan saran.

\section{HASIL DAN PEMBAHASAN}

Uji efektivitas media game education ini dimaksudkan untuk menguji seberapa signifikan pengaruh penggunaan media game education terhadap hasil pembelajaran siswa kelas 1. Peneliti mengumpulkan data pre-test dari 47 siswa kelas 1 MI Kota Salatiga (MI Ma'arif Mangunsari dan MI Tarbiyatul Islamiyah Noborejo) yang diberikan sebelum pembelajaran dimulai. Kemudian setelah selesai pembelajaran dilakukan posttest.

Tabel 1.1 Data Hasil Belajar Pretest dan Posttest Siswa dalam Menggunakan Media Pembelajaran Game Education

\begin{tabular}{ccccccc}
\hline \multirow{2}{*}{ No } & \multirow{2}{*}{ Nama } & \multicolumn{5}{c}{ Nilai } \\
\cline { 3 - 5 } & & Pretest & Ket & Posttest & Ket & \\
\hline 1 & A1 & 40 & TT & 90 & T & 70 \\
2 & A2 & 60 & TT & 80 & T & 70 \\
3 & A3 & 60 & TT & 80 & T & 70 \\
4 & A4 & 80 & T & 100 & T & 70 \\
5 & A5 & 40 & TT & 90 & T & 70 \\
6 & A6 & 60 & TT & 90 & T & 70 \\
7 & A7 & 60 & T & 90 & T & 70 \\
8 & A8 & 80 & T & 100 & T & 70 \\
9 & A9 & 60 & TT & 90 & T & 70
\end{tabular}


Rosidiana Ma'rufah, Abdul Ghoni

Pengembangan Media Pembelajaran Game Education pada Mata Pelajaran Bahasa Inggris..

\begin{tabular}{|c|c|c|c|c|c|c|}
\hline 10 & A10 & 80 & $\mathrm{~T}$ & 100 & $\mathrm{~T}$ & 70 \\
\hline 11 & A11 & 60 & $\mathrm{TT}$ & 100 & $\mathrm{~T}$ & 70 \\
\hline 12 & $\mathrm{~A} 12$ & 60 & $\mathrm{TT}$ & 100 & $\mathrm{~T}$ & 70 \\
\hline 13 & $\mathrm{~A} 13$ & 40 & $\mathrm{TT}$ & 90 & $\mathrm{~T}$ & 70 \\
\hline 14 & A14 & 80 & $\mathrm{~T}$ & 100 & $\mathrm{~T}$ & 70 \\
\hline 15 & A15 & 60 & $\mathrm{TT}$ & 90 & $\mathrm{~T}$ & 70 \\
\hline 16 & A16 & 60 & $\mathrm{TT}$ & 90 & $\mathrm{~T}$ & 70 \\
\hline 17 & $\mathrm{~A} 17$ & 40 & $\mathrm{TT}$ & 90 & $\mathrm{~T}$ & 70 \\
\hline 18 & A18 & 80 & $\mathrm{~T}$ & 80 & $\mathrm{~T}$ & 70 \\
\hline 19 & A19 & 60 & $\mathrm{TT}$ & 90 & $\mathrm{~T}$ & 70 \\
\hline 20 & A20 & 60 & $\mathrm{TT}$ & 80 & $\mathrm{~T}$ & 70 \\
\hline 21 & $\mathrm{~A} 21$ & 80 & $\mathrm{~T}$ & 90 & $\mathrm{~T}$ & 70 \\
\hline 22 & $\mathrm{~A} 22$ & 60 & $\mathrm{TT}$ & 80 & $\mathrm{~T}$ & 70 \\
\hline 23 & $\mathrm{~A} 23$ & 60 & $\mathrm{TT}$ & 80 & $\mathrm{~T}$ & 70 \\
\hline 24 & A24 & 60 & $\mathrm{TT}$ & 80 & $\mathrm{~T}$ & 70 \\
\hline 25 & A25 & 60 & $\mathrm{TT}$ & 100 & $\mathrm{~T}$ & 70 \\
\hline 26 & A26 & 40 & $\mathrm{TT}$ & 90 & $\mathrm{~T}$ & 70 \\
\hline 27 & A27 & 60 & $\mathrm{TT}$ & 80 & $\mathrm{~T}$ & 70 \\
\hline 28 & $\mathrm{~A} 28$ & 80 & $\mathrm{~T}$ & 80 & $\mathrm{~T}$ & 70 \\
\hline 29 & A29 & 60 & $\mathrm{TT}$ & 90 & $\mathrm{~T}$ & 70 \\
\hline 30 & A30 & 40 & $\mathrm{TT}$ & 80 & $\mathrm{~T}$ & 70 \\
\hline 31 & A31 & 60 & $\mathrm{TT}$ & 60 & TT & 70 \\
\hline 32 & A32 & 40 & $\mathrm{TT}$ & 70 & $\mathrm{~T}$ & 70 \\
\hline 33 & A33 & 60 & $\mathrm{TT}$ & 80 & $\mathrm{~T}$ & 70 \\
\hline 34 & A34 & 80 & $\mathrm{~T}$ & 80 & $\mathrm{~T}$ & 70 \\
\hline 35 & A35 & 40 & $\mathrm{TT}$ & 60 & TT & 70 \\
\hline 36 & A36 & 60 & $\mathrm{TT}$ & 70 & $\mathrm{~T}$ & 70 \\
\hline 37 & A37 & 60 & $\mathrm{TT}$ & 80 & $\mathrm{~T}$ & 70 \\
\hline 38 & A38 & 60 & $\mathrm{TT}$ & 80 & $\mathrm{~T}$ & 70 \\
\hline 39 & A39 & 80 & $\mathrm{~T}$ & 80 & $\mathrm{~T}$ & 70 \\
\hline 40 & A40 & 60 & $\mathrm{TT}$ & 90 & $\mathrm{~T}$ & 70 \\
\hline 41 & A41 & 60 & $\mathrm{TT}$ & 80 & $\mathrm{~T}$ & 70 \\
\hline 42 & $\mathrm{~A} 42$ & 80 & $\mathrm{~T}$ & 90 & $\mathrm{~T}$ & 70 \\
\hline 43 & A43 & 60 & $\mathrm{TT}$ & 80 & $\mathrm{~T}$ & 70 \\
\hline 44 & A44 & 50 & $\mathrm{TT}$ & 60 & TT & 70 \\
\hline 45 & A45 & 80 & $\mathrm{~T}$ & 80 & $\mathrm{~T}$ & 70 \\
\hline 46 & A46 & 80 & $\mathrm{~T}$ & 100 & $\mathrm{~T}$ & 70 \\
\hline 47 & A47 & 60 & $\mathrm{TT}$ & 80 & $\mathrm{~T}$ & 70 \\
\hline
\end{tabular}

$45 \quad$ Print - ISSN: 2443-0021

Online - ISSN: 2716-4136 
Mitra PGMI: Jurnal Kependidikan MI

Vol. 07 No. 01 Tahun 2021

\begin{tabular}{ccc}
\hline Jumlah & 2854 & 3990 \\
\hline Rata-Rata & 60.7 & 84.9 \\
\hline Jumlah Tuntas & 13 & 44 \\
\hline $\begin{array}{c}\text { Jumlah Tidak Tuntas } \\
\text { Prosentase } \\
\text { Ketuntuasan }\end{array}$ & 34 & 3 \\
\hline
\end{tabular}

Berdasarkan pada tabel di atas, maka dapat kita simpulkan bahwa adanya pengaruh yang cukup signifikan dalam penggunaan media pembelajaran game education terhadap hasil pembelajaran Bahasa Inggris khususnya materi my body. Dalam tabel tersebut menunjukkan bahwasanya sebelum menggunakan media game education ada $27,65 \%$ dari 47 siswa yang tuntas dalam pembelajaran. Setelah menggunakan media pembelajaran game education ada peningkatan yang signifikan dari hasil ketuntasan belajar siswa, yakni mencapai 93,62\% .

\section{UJI T}

\section{Independent Samples Test}

\section{T-Test}

Paired Samples Statistics

\begin{tabular}{|rr|r|r|r|c|}
\hline & Mean & N & $\begin{array}{c}\text { Std. } \\
\text { Deviation }\end{array}$ & $\begin{array}{c}\text { Std. Error } \\
\text { Mean }\end{array}$ \\
\hline \multirow{2}{*}{ Pair 1 } & Pretest & 61,4894 & 47 & 13,18410 & 1,92310 \\
& Posttest & 84,8936 & 47 & 10,39907 & 1,51686 \\
\hline
\end{tabular}

Pada tabel di bawah ini menampilkan hasil ringkasan statistik deskriptif dari hasil pretest serta postest.

Paired Samples Test

\begin{tabular}{|c|c|c|c|c|c|c|c|c|}
\hline & \multicolumn{5}{|c|}{ Paired Differences } & \multirow[t]{3}{*}{$\mathrm{t}$} & \multirow[t]{3}{*}{ df } & \multirow{3}{*}{$\begin{array}{l}\text { Sig. } \\
(2- \\
\text { tailed })\end{array}$} \\
\hline & \multirow[t]{2}{*}{ Mean } & \multirow[t]{2}{*}{$\begin{array}{c}\text { Std. } \\
\text { Deviatio } \\
\mathrm{n}\end{array}$} & \multirow[t]{2}{*}{$\begin{array}{l}\text { Std. } \\
\text { Error } \\
\text { Mean }\end{array}$} & \multicolumn{2}{|c|}{$\begin{array}{l}95 \% \text { Confidence } \\
\text { Interval of the } \\
\text { Difference }\end{array}$} & & & \\
\hline & & & & Lower & & & & \\
\hline Pair 1 & $-23,40426$ & 14,18459 & 2,06904 & $-27,56901$ & $-19,23950$ & $-11,312$ & 46 &, 000 \\
\hline
\end{tabular}

Keterangan:

1. Jika nilai Sig. (2-tailed) $<0,05$, maka terdapat perbedaan yang cukup signifikan antara hasil belajar pada data pretest dan posttest.

2. Jika nilai Sig. (2-tailed) sebesar $0,00<0,05$, maka tidak terdapat perbedaan yang signifikan antara hasil belajar pada data pretest dan posttest . 
Rosidiana Ma'rufah, Abdul Ghoni

Pengembangan Media Pembelajaran Game Education pada Mata Pelajaran Bahasa Inggris..

Kesimpulan: Setelah menganalisis hasil penelitian menggunakan SPSS, diketahui bahwa nilai Sig. (2-tailed) sebesar 0,000 $<0,05$, maka dapat di ambil kesimpulan bahwasannya terdapat perbedaan yang signifikan antara hasil pretest dan posttest dalam hasil pembelajaran sebelum dan sesudah menggunakan media pembelajaran game education.

\section{Proses Pelaksanaan Penggunaan Media Pembelajaran Game Education}

Dalam penggunaan media pembelajaran game education oleh guru kelas $1 \mathrm{MI}$ Kota Salatiga (MI Ma'arif Mangunsari dan MI Asas Islam Kalibening). Sebelumnya mereka belum pernah menggunakan media pembelajaran berupa game education dalam pembelajaran sehari-hari. Ini berpengaruh terhadap hasil pembelajaran yang ditunjukkan dengan rendahnya angka ketuntasan pembelajaran khususnya pada pembelajaran Bahasa Inggris materi my body pada siswa kelas 1 yang dilakukan dengan pemberian beberapa butir soal yang dimaksudkan sebagai pretest. Maka, selanjutnya para guru diberikan media pembelajaran game education yang dapat mereka manfaatkan untuk menarik minta siswa yang diharapkan juga mampu meningkatkan hasil kemampuan belajar mereka. Setelah digunakannya media pembelajaran game education ini beberapa siswa diberikan kembali beberapa butir soal atau yang dimaksudkan sebagai posttest.

\section{Efektivitas Penggunaan Media Pembelajaran Game Education}

Pada hasil pretest di dapatkan hasil rata-rata nilai sebesar 60,7 dengan angka ketuntasan sebesar $27,65 \%$. Kemudian dalam hasil posttest didapatkan hasil yang signifikan dengan hasil rata-rata sebesar 84,9 atau sebesar 93,6\% siswa tuntas dalam pembelajaran Bahasa Inggris materi my body. Ini membuktikan bahwasannya media game education ini layak digunakan sebaai salah satu media pembelajaran yang mampu membantu guru dalam menyampaikan materi pelajaran serta mampu menarik minat siswa sehingga mereka merasa mudah dan senang mempelajari dan menerima materi yang disampaikan oleh guru

\section{KESIMPULAN DAN SARAN}

Kesimpulan dari data di atas bahwa media pembelajaran game education layak digunakan, dapat membantu guru menyampaikan materi pelajaran serta mampu menarik minat siswa saat mempelajarai materi my body.

Penelitian ini tentunya jauh dari kata sempurna, maka dari itu besar harapan kami untuk dapat melanjutkan ke penelitian pengembangan berikutnya agar memperoleh hasil pengembangan yang baru dan lebih bagus.

\section{UCAPAN TERIMA KASIH}

Ucapan terima kasih kami sampaikan kepada selurus sivitas akademik keluarga besar IAIN Salatiga dan MI Maarif Mangunsari yang telah membantu proses berjalannya penelitian ini. 


\section{REFERENSI}

Aminudin, A. (2014). Media Pembelajaran Bahasa Arab. Al-Munzir, 7(2), 13-28. http://dx.doi.org/10.31332/am.v7i2.276.

Farouq, Faisal Anam. (2015). Inovasi Media Pembelajaran, Karya Tulis Mahasiswa, Universitas Surya Serpong, 13.

Karo-Karo, I. R. Rohani, R. (2018). Manfaat Media Dalam Pembelajaran. AXIOM: Jurnal Pendidikan \& Matematika, 7(1), 91-96. http://dx.doi.org/10.30821/axiom.v7i1.1778

Lestari, S. Y., Hadi, H., \& Mushafanah, Q. (2019). Pengaruh model problem based learning berbantu permainan edukatif terhadap hasil belajar tematik. Jurnal Sinektik, 2(1), 97-105. http://dx.doi.org/10.33061/js.v2i1.2979.

Nozomi, I. (2018). Aplikasi Game Edukasi pada Anak Usia 5 Sampai 10 Tahun dengan Metode Image Manipulation. INTECOMS: Journal of Information Technology and Computer Science, 1(2), 124-131. https://doi.org/https://doi.org/10.31539/intecoms.v1i2.288

Nugraha, J., Zulela, MS, \& Fuad, N (2020). Peningkatan Keterampilan Menulis Deskripsi Melalui Metode Problem Based Learning di Kelas IV SDN 3 Selajambe. DWIJA CENDEKIA: Jurnal Riset Pedagogik, 4(2), 226-236. https://doi.org/10.20961/jdc.v4i2.45278.

Rumainur. (2016). Pengambangan Media Ajar Berbasis Multimedia Autoplay Studio 8 Dalam Pembelajaran Sejarah Kebudayaan Islam Kelas XI MA Bilingual Batu Malang", Tesis, Universitas Negeri Maulana Malik Ibrahim.

Vitianingsih, A. V. (2016). Game Edukasi Sebagai Media Pembelajaran Pendidikan Anak Usia Dini." INFORM: Jurnal Ilmiah Bidang Teknologi Informasi dan Komunikasi, 1(1), 1-8. http://dx.doi.org/10.25139/ojsinf.v1i1.220. 